\begin{tabular}{c} 
International Journal of Engineering \& Technology, $7(2)(2018) 300-304$ \\
International Journal of Engineering \& Technology \\
Website: $\begin{array}{c}\text { ww. sciencepubco.com/index.php/IJET } \\
\text { doi: } 10.14419 / \text { ijet. } 7 \text { i } 2.9565 \\
\text { Research paper }\end{array}$ \\
\hline
\end{tabular}

\title{
Sustainable construction management in education sector
}

\author{
Subhav Singh ${ }^{1}$, Saurav Dixit ${ }^{2}$, Deekshant Varshney ${ }^{3}$ \\ ${ }^{1}$ Research Scholar, K R Mangalam University, Gurgaon, India \\ ${ }^{2}$ Research Scholar, RICS School of Built Environment, Amity University, Noida, India \\ ${ }^{3}$ Research Scholar, K R Mangalam University, Gurgaon, India \\ *Corresponding author E-mail: er.subhav@hotmail.com
}

\begin{abstract}
The purpose of the study is to understand and identify the current courses on sustainability in construction in leading universities in India. The study is conducted on pan India basis and different courses have been compared and results were drawn. The research is conducted using a structured questionnaire survey from the respondents through all over India. Keeping in mind the end goal to evaluate the heartiness of the course educational programs at School of civil engineering K R Mangalam University, a correlation was led with establishment's offering comparable projects. The findings of the study conclude that the curriculum at School of civil engineering K R Mangalam University is effective in imparting sustainability concepts in the built environment domain. The students who have progressed towards the end of the course appeared to have achieved a good level of understanding of both the general and specific aspects of sustainability and its applications to the built environment. With expanding the effect of human survival on condition and unending civil argument of our duty towards who and what is to come, sustainability has made some amazing progress.
\end{abstract}

Keywords: Building; Construction Management; Education; India; Sustainable Construction.

\section{Introduction}

The long haul effect of human utilization designs is obvious through environmental change and over the use of normal assets comprehensively. The commitment of the development business towards over usage of characteristic assets and high vitality utilization both amid development and tasks of structures is vast [1]. The development segment universally represents one-fifth of the vitality utilization [2]. The Indian development industry isn't a long ways behind, representing near $40 \%$ of aggregate vitality utilization in the nation. It is required to develop to USD 1 trillion a year showcase by 2025 , as indicated by an investigation by Global Construction Perspectives and Oxford Economics. The purpose of this development spurt is ascribed to the flourishing urbanization rate, with 10.4 million additional occupants just in the Indian Capital alone. The report additionally predicts that India will overwhelm Japan by 2030 , to be the third biggest worldwide development showcase. The significant accentuation in the building stock to be in the territories of lodging and framework, with an expected lodging interest of near 170 million to be worked by 2030 alone. With this sort of interest, it is vital that means are taken to guarantee that the development business holds onto supportability as a centre ethos. This exploration goes for evaluating School of civil engineering K R Mangalam University endeavours at engaging future development professionals' to understand the importance of being genuinely feasible. The accompanying segments examine the surviving writing apropos to the present talk in maintainability in development administration education.

\section{Literature review}

With creating nations battling for a more noteworthy part in this changing financial and ecological worldwide situation, the part of education in advancing manageable advancement among the young has risen to be of prime significance [3]. The Brundtland Commission gave the world an expansive meaning of Sustainable Development in 1987 as "Maintainable advancement is an improvement that addresses the issues of the present without bargaining the capacity of future ages to meet their own particular needs" [4]

[5] have gotten a different definition from this for manageable development as "those materials and strategies used to build and keep up a structure that addresses the issues of the present without bargaining the capacity of future ages to address their own particular issues" [5] The earth and all its resources are a mutual save that we as people have utilized and continue to send past its holding limit. The building and construction industry, inside the area of the assembled condition, frames the biggest shopper, having a broad effect on the earth and characteristic assets. It likewise has a more noteworthy duty and a larger part to play in contributing towards the Sustainable motivation. Therefore, with expanding populace, worldwide financial improvement, the current worldwide utilization praise terns and reliance on non-inexhaustible assets, the need to include Sustainability in instructive projects for the fabricated environment is vital [6].

As [7] noticed, the general plan is to accomplish a foundational integration to fabricate associations and sharpen understudies and directors to think, work and feel diversely with respect to the idea of sustainability [7]. It is imperative to survey how the present age of graduates in development administration comprehend the significance of reasonable advancement. The part of instructors isn't 
constrained to guaranteeing that the course educational programs is according to college prerequisites yet in addition, how well the youthful personalities are being conditioned to confront the difficulties and steer business choices towards or in arrangement with practical advancement [8]-[10] Accordingly, the larger objective of construction teachers is to confer responsive instruction, one that instills maintainability as an inalienable venture driver and not similarly as an extra goal. At the School of civil engineering K R Mangalam University, the academic approach is centred towards an all-encompassing comprehension of supportable improvement as it applies to the Built Environment. As School of civil engineering K R Mangalam University readies its understudies in the field of development administration and business practices, it is essential that we survey, how our instruction is affecting the potential assembled condition experts who speak to the future leaders.

The early models of business training basically centred on educating potential supervisors keeping in mind the end goal to amplify returns for proprietors and financial specialists [11]. The business instruction has focused on 'centre ideas like back, bookkeeping with insignificant consideration of training on Ethics, Corporate Social Responsibility and Sustainability' [12]. The Bruntland Commission Report changed this observation as it contended for a noteworthy part of the business in accomplishing practical advancement. The report denoted a defining moment in business training and was trailed by a request on "organizations to operationalize idea of supportable advancement to address they're negative social and environmental impacts" [11]. With the turn of the century, the requirement for joining maintainability in administration training has been additionally underlined: the United Nations Global Compact has influenced an undertaking to adjust the Sustainable to treatment Goals with the Principles of Responsible Management Education. Development Management is a course in the conjunction of the designing and the administration trains, the requirement for a feasible point of view in this field is essential [8] In an examination done by [11], it was discovered that the vast majority of the significant business colleges on the planet have included some sort of activity concentrating on supportability [11]. However, such activities are only extremities deeply course educational modules. These activities are minor "seat pack" issues which are slopes far from the central subjects, to be tended to when the 'meat' or the genuine substance of the coursework is finished [11]. Understudies in the manufactured condition disciplines go-ahead to become development experts, instructors and analysts among expecting different parts. It is basic that these forthcoming professionals are set up to manage the provisioning and upkeep of the fabricated condition and settle on choices for a more maintainable future [6]. This moulding of these youthful personalities relies upon the mindfulness, information, abilities and qualities they get amid their essential time of concentrate in the college [13] [14] stressed that "foundations of higher education are vital spots of generation, propagation and dissemination of information". These foundations all-inclusive perceive that they have a one of a kind obligation towards the objective of accomplishing sustainability and have received practices and course educational program to this end. The college is a judicious situation for uniting diverse and discrete thoughts on maintainability and coordinating the idea into the pertinent instructive educational program [13]. With the focal point of advancement moving to the 'low and centre in-come nations' there is a lot of development air conditioning activity conceived to happen in these nations. Along these lines, there is a need to build up a committed workforce of undertaking pioneers who are capable of the working of the development industry and can satisfy its requests without bargaining the ethos of supportable advancement.

While India was as of late delegated "bring down centre pay" continuous attempt by World Bank, the financial improvement over the most recent couple of years has unquestionably pushed it to the worldwide outskirts. In mid-2015, India declared a yearning environmental change strategy to decrease the force of carbon discharges by $33-35 \%$ by 2030 from 2005 levels and change to $40 \%$ non-non-renewable energy source in vitality blend by 2030
(Accenture, 2015). What's more, India intends to fourfold its sustainable power source limit and extension the vitality supply and demand hole by 2022 . With such vitality effectiveness focuses on, the Indian business condition is step by step moving towards an attitude that acknowledges and comprehends the advantages of more prominent asset proficiency. Moreover, in the CDP report for 2015, a large portion of the taking part private and open division corporations have announced a decrease in discharges and in this manner their effect on the atmosphere, by utilization of vitality productivity measures. Along these lines, the business condition in India is steadily remoulding itself to be comprehensive of supportable undertakings and activities. This trans-arrangement focused on India's dedication towards maintainability is undoubtedly an overwhelming test, one that requires future business decisions to be taken with supportability as an essential partner, yet in addition, one that requires that our future business pioneers are sufficiently adapted to comprehend and acknowledge manageability and can likewise advance past its objectives. The open doors being made inside this changing business environment are plenty and the need to address how our education system has indeed stepped up to prepare the business professionals becomes essential. According to research conducted by [15], the need to include environmental sustainability, ethical decision-making and social responsibility in management education within the Indian context is centred on two factors. First is the external pressure from the newfound societal relevance of concepts of social, economic and environmental responsibility and second due to a greater internal pressure by faculty who have focussed their research on business and natural environment [15].

As unmistakably archived, the development part has a more prominent part and obligation in general commitment towards maintainability in the constructed condition, as it bears the most extreme response to extemporize vitality and asset productivity [8]Furthermore, with more noteworthy information semi country of advantages of economic improvement, there is a need to plan administration graduates with ideas of supportability [12]. Alongside development education, the administration training has an equivalent part to play in leading the way towards accomplishing supportable development. Together, these two divisions have a significant commitment to India accomplishing its reasonable objectives. The School f civil engineering K R Mangalam University serves these two particular industry segments as it gives a business organization degree in development venture administration, it takes into account two basic areas of development industry and business administration segment.

\section{Research aim and objectives}

This examination plans to assess the effect of development oversee coursework on the apparent comprehension of postgraduate understudies in ideas of supportability as it applies to the constructed environment. In perspective of this exploration point the examination targets are as per the following:

1) Understand the present condition of learning of development management understudies in the field of economic development.

2) Conduct an associate survey of supportability focussed postgraduate coursework with different schools offering comparable projects to evaluate the pertinence of giving practical learning in development administration instruction

3) Evaluate the part obviously educational modules in moulding the learning base of understudy amass in the domain of supportable development/supportability

4) Analyse learning movement in understudies as they step by step move towards their course finish.

5) Evaluate application and significance of learning relating to manageable development, obtained amid coursework by late graduates in business/venture situations 


\section{Research methodology, research aim and objectives}

The strategy followed in this exploration is sketched out in Figure 1 and comprised of a writing audit, trailed by an examination of coursework of School of civil engineering K R Mangalam University with five other chose schools and finished in a review survey of understudies at School of civil engineering K R Mangalam University. The correlation of coursework helped the specialists to accomplish target 2 and is expounded underneath. To satisfy goals $1,3,4$ and 5 , the poll review was completed.

The survey respondents were divided into three cohorts as shown below.

Error! Reference source not found.Table 1: Survey Respondent Composition and Characteristics

\begin{tabular}{lll}
\hline $\begin{array}{l}\text { Cohort } \\
1\end{array}$ & $\begin{array}{l}\text { Incoming students in the postgraduate pro- } \\
\text { gram at School of civil engineering K R } \\
\text { Mangalam University }\end{array}$ & $\begin{array}{l}\text { Second Semes- } \\
\text { ter Students }\end{array}$ \\
\hline $\begin{array}{l}\text { Cohort } \\
2\end{array}$ & $\begin{array}{l}\text { Outgoing students in the postgraduate pro- } \\
\text { gram at School of civil engineering K R } \\
\text { Mangalam University }\end{array}$ & $\begin{array}{l}\text { Fourth Semes- } \\
\text { ter Students }\end{array}$ \\
$\begin{array}{l}\text { Cohort } \\
3\end{array}$ & Recently placed graduates & $\begin{array}{l}\text { Recently } \\
\text { Placed Stu- } \\
\text { dents }\end{array}$ \\
\hline
\end{tabular}

The survey was open for seven weeks from November 27, 2016, to January 15, 2017, to the student cohorts at School of civil engineering K R Mangalam University. A total of 271 responses were recorded and included in the student survey.

The survey consisted of three parts: the first part contained questions testing general awareness regarding sustainability, the second part comprised of questions testing specific knowledge of sustainability within the domain of the construction industry; and the third part dealt with the perception of the importance given to sustainability in the Indian construction industry. Part 1 and 2 were relevant in gauging information from the perspective of research objectives 1, 3 and 4; while part 3 was helpful in reaching research objective 5 .

Cohort 1 was only required to take the first two parts of the survey, while the Cohort 2 and 3, who had been exposed to the construction industry through internship and/or professional experience, answered all three parts. Questions were targeted towards specific areas, to assess topics understood to be relevant from the literature survey.

Part 1 and 2 of the survey were designed considering the issue that in many courses, sustainability is taught only as an introductory course and not as an in-depth one and that students often lack awareness about the specific meaning of concepts related to sustainability. Questions were also targeted to understand whether sustainability-education was integrated with the rest of the course [1] [7] [15], whether the knowledge is only theoretical or practical applications were emphasized upon (McDonald, 2004), and whether students got an opportunity to probe into research during the coursework [16] [17]. Part 3 was designed to examine the market demand, awareness and acceptability of sustainability in the Indian market. The focus of some questions was also to understand how well the classroom knowledge is addressing the industry needs and practices [1]. As eventually, classroom knowledge seeks solutions through the implementation of concepts.

\subsection{Program Comparison}

Keeping in mind the end goal to evaluate the heartiness of the course educational programs at School of civil engineering K R Mangalam University, a correlation was led with establishment's offering comparable projects. The chose foundations were, School of Planning and Architecture (SPA), Delhi, Indian Institute of Technology, Madras (IIT-M), Indian Institute of Technology, Delhi (IIT-D), National Institute of Construction Management and Re-seek, Pune (NICMAR) and Center for Environmental Planning and Technology, Ahmedabad (CEPT). Every one of the organizations mentioned above leads a postgraduate program in development management/Building Engineering and Management/Construction Engineering and Management. The creators directed an examination of development administration coursework at the previously mentioned institutions to analyze the consideration of supportability ideas in constructed condition division. The program examination uncovered that School of civil engineering K R Mangalam University has a complete twist towards consideration of maintainability in the program structure by giving supportability focussed courses, for example, 'Feasible Practices for Construction' and 'Propelled Energy Management'. Notwithstanding these compulsory courses, a few sections of general courses likewise cover maintainability viewpoints, for example, 'BIM for Built Environment: Sustainability Modelling and Environmental Analysis' and 'Lean Practices in Construction Projects: Linkages of Lean and Green Concepts in Design of Built Environment', and so forth. It was likewise watched that IIT-D has no essential courses that offer a comprehensive learning in supportable development rehearse, be that as it may, an elective course titled 'Feasible Materials and Green Buildings' is accessible for understudies. IIT-M takes a comparable example for imperative courses however offers a large group of courses focusing on environmental examinations identified with all parts of the assembled condition. Additionally, with an engaged gathering of the ecological program inside the structural designing system, both IIT-D and IIT-M have proficient specialists with huge involvement in green building consultancy and natural effect evaluation for foundation ventures. Similar, CEPT has no imperative course yet an elective named 'Indian culture and feasible development practices' which is available to both undergrad and postgraduate understudies.

SPA Delhi has an imperative course named, 'Ecological Clearances' which counts Environmental Impact Assessment and similar statutory bylaws required for venture endorsements. CEPT and SPA Delhi both fundamentally being outline schools, have an exceptionally solid base of structural and arranging experts that teach a solid instructional method which is comprehensive of reasonable plan rehearses in development and framework divisions. Subsequently, as opposed to having an express presentation to subjects identified with supportability or green forming outline, the understudies at CEPT and SPA Delhi get a more implicit introduction to these ideas. NICMAR has additionally picked an elective course called 'Green construction administration'. Therefore, it can be securely accepted that the student marks who don't settle for this elective have no chance to get off being ex-postured to ideas on green building practices and supportability in manufactured condition.

\section{Overview key findings}

The overview uncovered data that was predictable with the literature study. The reactions from understudies confirmed that course educational programs at School of civil engineering K R Mangalam University considerably affects expanding understudy learning and mindfulness on maintainability concepts. Likewise, there were a few occasions and rivalries notwithstanding coursework that instilled the requirement for self-learning of such ideas by understudies. One such illustration is the yearly occasion of "Green Building Week". The occasion is a mixture of Dialogues with Industry Experts on Sustainable Construction, Work-shops from Design and Construction Companies actualizing supportability works on, exhibiting hands-on thoughts and encounters and understudy rivalries on manageability rehearses in the manufactured environment. Such occasions have been instrumental in making an environment of detached and self-learning for understudies at School of civil engineering K R Mangalam University. Correlation between the reactions from the first and second parts of the review uncovered a significant information development in marks' comprehension of maintainability ideas as they advanced 
through the program at School of civil engineering K R Mangalam University. Both the accomplices of the fourth semester and graduated class understudies performed superior to the secondsemester understudies. This was evaluated through T-tests. The $\mathrm{p}$ esteem for one-followed t-test for fourth-semester understudies was 0.00019 and 0.04514 for graduated class separately. Figures 1 , and 2 show a fundamentally better execution of fourth-semester stu-gouges and can be ascribed to essential and elective courses in sustainability that are offered amid the third semester of the program at School of civil engineering K R Mangalam University. It was additionally discovered that presentation of manageability at undergrad instruction is fundamental in shaping a solid establishment that aides in building up a more comprehensive point of view for development professionals. It was observed that undergraduate course learning or self-learning in concepts of sustainability by students helped to establish a strong knowledge base and develop a perspective to comprehend and appreciate sustainability practices in construction. As shown in Figure 3, this was apparent in survey responses from second-semester students, as they scored less than their peers who were familiar with Green Buildings in their undergraduate course in some form or other. We performed t-tests to investigate whether the second-semester student-group unfamiliar with Green Buildings was outperformed by the other groups of second semester students at a statistically significant level, and the p-values of the one-tailed t-test were, 0.024461 (Significant) for unfamiliar vs. those who had come across the term 'Green Building', in spite of there is no dedicated course on the issue; 0.022965 (Significant) for unfamiliar vs. those who had a dedicated course/chapter(s) on green buildings and 0.027732 (Significant) for unfamiliar vs. those who learnt about Green Buildings on their own. Thus, for second-semester students, there was a statistically significant gap between students who had been unfamiliar with green buildings at the undergraduate level and students who had been familiar, based on measuring the performance in the basic questions. Program structure and course curriculum at School of civil engineering K R Mangalam University have a significant impact in filling gaps in sustainability knowledge from the Students' undergraduate education and successfully ringing all students to a level platform. This was an important observation and learning for School of civil engineering $K$ $\mathrm{R}$ Mangalam University, as the students entering the program come from a diverse spectrum of undergraduate courses.

In order to assess this, t-tests were performed to investigate whether the performance-gaps between the fourth-semester student group unfamiliar with green buildings and each of the other three groups, familiar with green buildings on various levels during their undergraduate studies are statistically significant. Among the p-values of the one-tailed t-tests, the only significant one is for the student group unfamiliar with green buildings vs. those who learnt about green buildings on their own. This proves that the gap between students is adequately bridged by their fourth semester regardless of their exposure to green buildings in their undergraduate coursework. Thus, reinforcing that the School of civil engineering K R Mangalam University curriculum acts effectively in imparting knowledge about sustainability to the students.

One of the survey questions addressed to both fourth-semester students and alumni attempted to gauge student perception regarding the relevance of classroom knowledge in sustainability. The intent of this question was to recognize whether the students understood why they are studying sustainability concepts, and also act as a sense check for staying abreast of current industry practices. This is extremely relevant as the sustainability practices are ever evolving. As shown in Figure 1, the survey revealed that $36 \%$ of both, fourth semester students and alumni think that classroom knowledge is extremely relevant, $36 \%$ of fourth semester students and $30 \%$ alumni think that classroom knowledge is somewhat relevant, $11 \%$ of fourth semester students and $4 \%$ alumni think that "Other sustainable methods" exist which are more relevant than what is being taught in classroom.

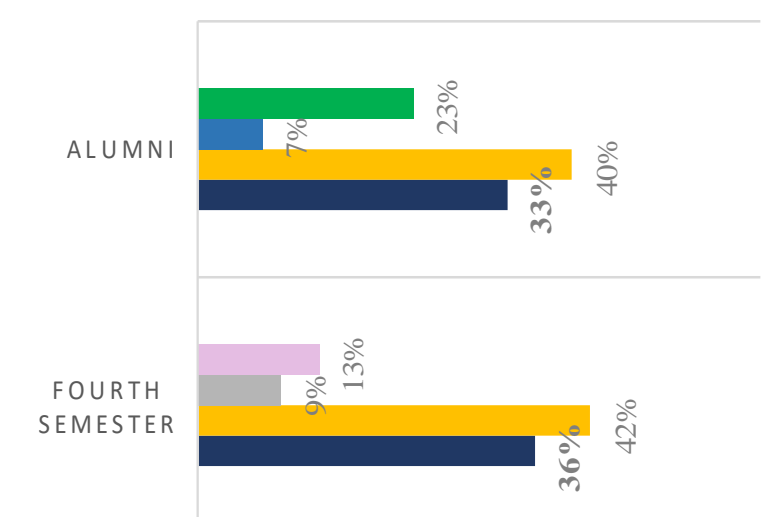

Scope for application of sustainable methods in the industry is limited

- Other sustainable methods exist, which are more relevant than what we learnt in classroom

Classroom Response is somewhat relevant

Fig. 1: Relevance of Classroom Knowledge in Industry.

Additionally, $9 \%$ of fourth-semester students and $23 \%$ alumni reported that scope for application of sustainable methods in the industry is limited. These figures represent that fourth-semester students are more optimistic about the application of sustainable techniques in the construction industry and the alumni, based on industry interaction after their course completion has come across newer sustainability concepts and practices, in the realm of the built environment.

Close to $36 \%$ of fourth-semester students and $33 \%$ of the alumni surveyed felt confident that they have inculcated knowledge about sustainability, sustainable construction guidelines and capability to solve real-life problems from a sustainable perspective. This implies that the percentage of students receiving the full spectrum of sustainability-related education has increased from the alumni to the fourth-semester students.

However, the percentage of students who reported to have learnt about sustainability and guidelines for sustainable construction is $42 \%$ for fourth-semester students and $40 \%$ for the alumni. The percentage of students reported to have learnt about sustainability only without guidelines or real-life problems has increased from $23 \%$ in the alumni to $13 \%$ in the fourth-semester students. This points towards the need to create greater knowledge depth for final semester students by the inclusion of elective courses that provide focused vertical knowledge of more complex sustainability concepts in the built environment.

One of the questions in the survey also addressed inclusion of sustainable concepts in courses other than those whose primary focus is sustainability, which is an issue highlighted in several texts of the literature survey [1], [16] The response received as shown in Figure 2, reinforces that while the School of civil engineering K R Mangalam University curriculum has a considerable focus on including general concepts of sustainability, there is a large percentage of students for whom greater knowledge penetration is still necessary.

Presence of a strong research focus in a construction management program provides greater learning opportunities for students. This is all the more relevant when it comes to sustainability aspects of construction management [17] [18], [19]. As observed in the survey, $17 \%$ of students reported that they have been made familiar with the sustainability-related research, $47 \%$ have looked for research once/few times, $25 \%$ many times, while $11 \%$ refer to sustainability research on a regular basis. Therefore, a large percentage i.e., $87 \%$ of students have been familiar with sustainabilityrelated research during their coursework at School of civil engineering K R Mangalam University. Regarding the perceived importance of sustainability in the Indian construction industry, 
fourth-semester students were asked to rank the perceived importance of sustainability in the Indian Construction Industry. $42 \%$ students and $40 \%$ alumni reported that "Extreme Importance" is given to sustainability in the Indian construction industry, 23\% students and 13\% alumni think it is of "Moderate Importance"; $18 \%$ students and 21\% alumni think it is "Occasional Importance"; $13 \%$ students and 23\% alumni think it is "Extremely Rare Importance", while $1 \%$ students and $2 \%$ alumni think it is "No Importance". The students seem to have a more optimistic view regarding importance given to sustainability in the industry: giving the rating scores (like in a Likert scale) from 1 to 5, the mean score of the students is 3.97 while that of the alumni is 3.75 . However, there is no statistically significant difference in the t-test values.

\section{Conclusion}

The survey indicates that the curriculum at School of civil engineering K R Mangalam University is effective in imparting sustainability concepts in the built environment domain. The students who have progressed towards the end of the course appeared to have achieved a good level of understanding of both the general and specific aspects of sustainability and its applications to the built environment. The knowledge gap that existed between students due to different levels of exposure to sustainability in their undergraduate coursework, is aptly bridged towards the culmination of the program at School of civil engineering K R Mangalam University. In addition, the coursework is successful in imparting the exact meanings and significances of technical terms relating to sustainability as outlined in the literature review [20], [21]. Furthermore, the program at School of civil engineering K R Mangalam University creates an environment comprising of both active and passive knowledge means for student learning. The survey also highlighted a few areas that require greater focus, such as the need to create greater depth of knowledge in the application of sustainability concepts, while a majority of students undergo research work in their course of study but it is important for the students to see the implementation of these learned concepts. Focussed sustainability training and student competitions at School of civil engineering K R Mangalam University have been instrumental in achieving this end. Greater participation from industry mentors in sustainable practices coupled with events such as the "Green Building Week" has also been an ongoing effort at School of civil engineering K R Mangalam University.

Survey responses also indicate that there has been an effort to integrate the sustainable approach in the fold of general courses, specifically, whose main focus is other than sustainability. The coursework at School of civil engineering K R Mangalam University addresses sustainability, not as fragmented concepts but attempts to include them in relevant coursework as an important stakeholder. This helps the students to form an inclusive and sustainable perspective that they can build on through the program and also once they become part of the industry. As Conte points out, sustainability should permeate into construction curricula as an integral component, similar to conventional parameters of cost, time and quality[22] [2], as the focus has to be on a systemic integration of sustainable concepts in curricula.

Regarding the existence of sustainable approaches in the Indian construction industry, students, who have been less exposed to the industry, seem to be more optimistic than construction professionals. Likewise, as [8] properly note in their exploration that "Development can possibly improve as opposed to debase the earth and to advance as opposed to Madden social and economic value. In the event that this potential is to be acknowledged, everybody inside the business should accomplish some level of maintainability proficiency" [8] In the light of the financial and urban improvement in India, there is a distinct chance to make a comprehensive and supportable intercession in the ability that enters the Indian Construction Industry. There is a distinct interest for adequately prepared experts that can direct the improvement in India in a more manageable way. At School of civil engineering K R
Mangalam University, we are making the correct condition for understudy learning and development that expands on the development information and develop their basic capacities to set them up to be stewards of improvement that is really comprehensive and supportable

\section{References}

[1] U. Iyer-range, P. Arcari, and J. P. C. Wong, "Education for sustainability in the built environment: what are students telling us?' Procs 26th Annu. ARCOM Conf., no. September, pp. 1447-1456, 2010.

[2] E. Conte, "Sustainability and Built Environment: The role of Higher Education in Architecture and Building Engineering," Eur. J. Sustain. Dev., vol. 6, no. 3, pp. 1-10, 2016.

[3] R. O. Horwath, "the United States Patent 191," 1983.

[4] O. J. Olaniran, "The effects of cost-based contractor selection on construction project performance," J. Finance. Manag. Prop. Constr., vol. 20, no. 3, pp. 235-251, 2015 https://doi.org/10.1108/JFMPC-06-2014-0008.

[5] A. K. Tinker and R. Burt, "Greening' the Construction Curriculum," ASC Proc. 39th Annu. Conf., no. April, pp. 113-118, 2003.

[6] S. Holdsworth and O. Sandri, "Sustainability Education and the Built Environment: Experiences from the Classroom," J. Educ. Built Environ., vol. 9, no. 1, pp. 48-68, 2014. https://doi.org/10.11120/jebe.2014.00011.

[7] E. Raufflet, "Integrating Sustainability in Management Education," Humanities, vol. 2, no. 4, pp. 439-448, 2013. https://doi.org/10.3390/h2040439.

[8] P. E. Murray and A. J. Cotgrave, "Sustainability literacy: the future paradigm for construction education?" Struct. Surv. vol. 25, no. 1, pp. 7-23, 2007. https://doi.org/10.1108/02630800710740949.

[9] A. Murray, K. Skene, and K. Haynes, "The Circular Economy: An Interdisciplinary Exploration of the Concept and Application in a Global Context," J. Bus. Ethics, no. May, pp. 0-37, 2015.

[10] K. W. Chau, "Explaining Total Factor Productivity Trend in Building Construction: Empirical Evidence from Hong Kong," Int. J. Constr. Manag., vol. 9, no. 2, pp. 45-54, 2009. https://doi.org/10.1080/15623599.2009.10773128.

[11] M. Samari, N. Godrati, R. Esmaeilifar, P. Olfat, and M. W. M. Shafiei, "The investigation of the barriers in developing green building in Malaysia," Mod. Appl. Sci., vol. 7, no. 2, pp. 1-10, 2013. https://doi.org/10.5539/mas.v7n2p1.

[12] D. Haski-Leventhal and J. Concato, "The State of CSR and RME in Business Schools and the Attitudes of their Students," p. 38, 2016.

[13] S. Ameh, A. Dania, I. Zubairu, and S. Bustani, "Sustainable Construction Education: Assessing the Adequacy of Built Environment Professional' S Training," no. July, pp. 27-28, 2010.

[14] B. Jørgensen and S. Emmitt, "Lost in transition: the transfer of lean manufacturing to construction," Eng. Constr. Archit. Manag., vol. 15, no. 4, pp. 383-398, 2008. https://doi.org/10.1108/09699980810886874.

[15] M. N. Zadeh, "Environmental Ethics and Integrating Sustainability into Management Education," vol. IV, no. 1, 2011.

[16] S. Dixit, S. N. Mandal, A. Sawhney, and S. Singh, "Relationship between skill development and productivity in construction sector: A literature review," Int. J. Civ. Eng. Technol., vol. 8, no. 8, 2017.

[17] A. Ganah, A. Pye, and G. Hall, "the Role of Knowledge Transfer in Sustainability Research in the Built Environment Discipline," Construction, no. September, pp. 299-307, 2008.

[18] A. K. Pandey, S. Dixit, S. Bansal, S. Saproo, and S. N. Mandal, "Optimize the infrastructure design of hospital construction projects to manage hassle free services," Int. J. Civ. Eng. Technol., vol. 8, no. 10,2017 .

[19] A. Sao, S. Singh, S. Dixit, A. K. Pandey, and S. Singh, "Quality, productivity and customer satisfaction in service operations: An empirical study," Int. J. Mech. Eng. Technol., vol. 8, no. 10, 2017.

[20] S. Dixit, S. N. Mandal, A. Sawhney, and S. Singh, "Area of linkage between lean construction and sustainability in indian construction industry," Int. J. Civ. Eng. Technol., vol. 8, no. 8, pp. 623-636, 2017.

[21] S. Dixit, A. K. Pandey, S. N. Mandal, and S. Bansal, "A study of enabling factors affecting construction productivity: Indian scnerio," Int. J. Civ. Eng. Technol., vol. 8, no. 6, 2017.

[22] S. Singh, A. Bala, S. Dixit, and D. Varshney, "Critical analysis of causes of delay in residential construction projects in India," Int. J. Civ. Eng. Technol., vol. 9, no. 1, 2018. 